\title{
Determination of Some Mechanical Properties of Ugu Seed (Telfairia occidentalis) in Relation to the Design of Cracking Machine
}

\author{
Michael Mayokun Odewole ${ }^{1 *}$, Oluwatosin Adedamola Adesoye $^{2}$ \\ and Oluwatosin Adesola Shadare ${ }^{1}$ \\ ${ }^{1}$ Department of Agricultural and Biosystems Engineering, Faculty of Engineering and Technology, \\ University of Ilorin, PMB 1515, Ilorin, Kwara State, Nigeria \\ ${ }^{2}$ Department of Mechanical Engineering, Faculty of Engineering and Technology, University of Ilorin, \\ PMB 1515, llorin, Kwara State, Nigeria
}

\begin{tabular}{|c|c|}
\hline Abstract & Article Information \\
\hline \multirow{15}{*}{ 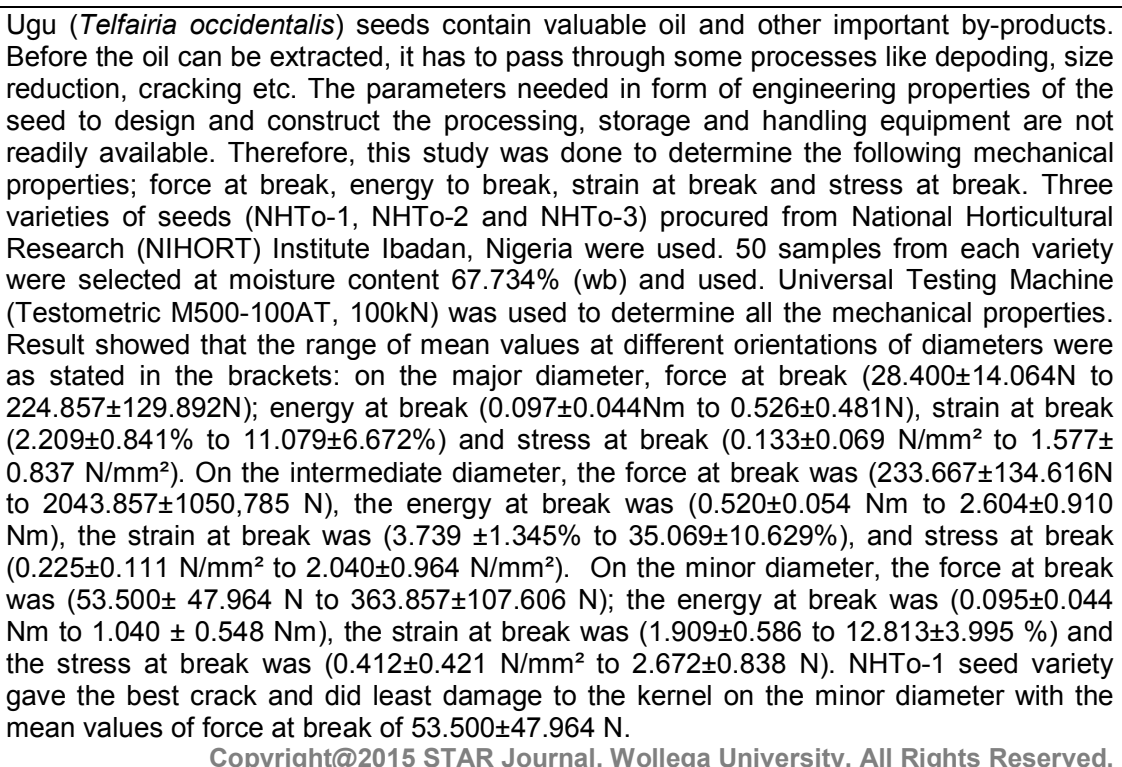 } & flstory: \\
\hline & Received : 03-06-2015 \\
\hline & : 04-09-2015 \\
\hline & Accepted : 23-09-2015 \\
\hline & Keywords: \\
\hline & Mechanical properties \\
\hline & Varieties \\
\hline & Ugu seed \\
\hline & Force at break \\
\hline & Energy to break \\
\hline & break \\
\hline & \\
\hline & \\
\hline & ael Mayokun Odewole \\
\hline & ail: \\
\hline
\end{tabular}

\section{INTRODUCTION}

Fluted pumpkin (Telfairia Occidentalis) is popularly called "Ugu" by the Igbo ethnic group of Eastern Nigeria. It is a creeping leafy vegetable that spreads low across the ground with large lobed leaves, and long twisting tendrils (Horsfall and Spiff, 2005; Christian, 2006; Ojiako and Igwe, 2008). In some West African countries (Ghana, Nigeria and Sierra Leone), the vegetable is usually grown for its commercial values (Nkang et al., 2003).

Grubben and Denton (2004) reported that the oil from the seed can be used as drying oil for paints and varnishes. In terms of food values, Alegbejo (2012) submitted that the high value of amino acids in Ugu seed is comparable with that of soybean meal with $95 \%$ biological value; and the young leaves of the plant contain the anti-nutrients cyanide at $60 \mathrm{mg} / 100 \mathrm{~g}$ dry matter and tannins at $41 \mathrm{mg} / 100 \mathrm{~g}$ dry matter.
An in-depth knowledge of mechanical properties of food, agricultural and other biological materials is very important when dealing with stress distribution under load. These properties are needed when designing size grading machine in electrostatic separation of grain and seed in colour evaluation (Mohsenin, 1970).

Mechanical properties of agricultural, food and other biological materials are those having to do with behavior of materials under applied forces. Mechanical properties are required to design equipment for proper handling, conveying, separation, drying, aeration, storing and processing of agricultural, food and other biological materials.

The seed (Ugu Seed) contains valuable oil and other useful by-products. Before the oil can be extracted, it has 
Michael Mayokun Odewole et al.,

to pass through some operations like handling, cracking, separation, size reduction etc. The parameters needed in form of engineering properties of the seed to design and construct effective processing, storage and handling equipment are not readily available. Therefore, the objective of this study was to determine some selected mechanical properties (force, energy, strain and stress) of Ugu seed with particular emphasis on the properties determined at the point of break.

\section{MATERIALS AND METHOD}

\section{Experimental Equipment}

The equipment used for the study was Universal Testing Machine (Testometric M500-100AT, 100kN) at the National Centre for Agricultural Mechanization, IlorinLokoja, Express Way, Kwara State, Nigeria.

\section{Procurement and Selection of Experimental Materials}

The material used was Ugu seeds (Telfairia Occidentalis). Matured pods ( 13 weeks old) containing the seeds were procured from the National Horticultural Research Institute (NIHORT) Ibadan, Nigeria. Three seed varieties were procured for the experiment. The seeds (Figure 1) were classified according to NIHORT standard based on the shape of the pods which were NHTo-1 (pointed at both ends), NHTo-2 (flat at point of attachment to the vine) and NHTo-3 (flat at both ends).

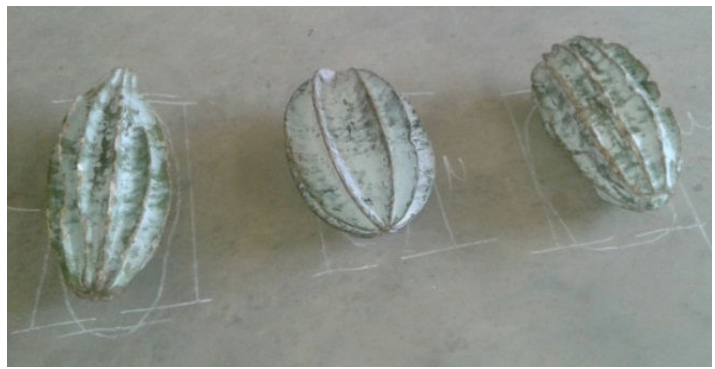

Figure 1: From left to right (NHTo-1, NHTo-2 \& NHTo-3)

\section{Seed Preparation}

The external coat (pods) of the seed was removed manually with the aid of a sharp knife in order to get seeds needed for the experiment. All the seeds were then fairly sun dried and the moisture content was estimated and the average value was $67.734 \%$ (wb). All foreign materials such as dust, stones, immature and broken seeds as well as bad seeds were separated by hand picking and the best seeds with no external observable defects were selected for the experiment. Figure 2 and 3 show the seeds before and after drying respectively.

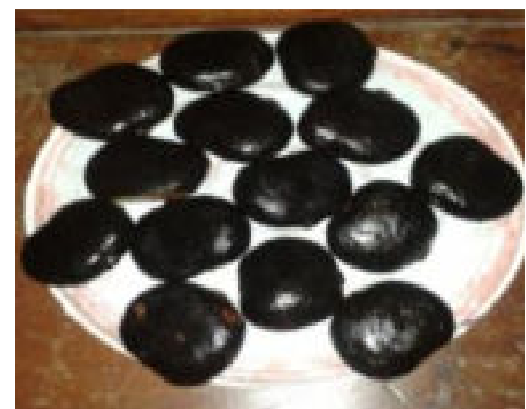

Figure 2: Seeds before drying
Sci. Technol. Arts Res. J., July-Sep 2015, 4(3): 187-191

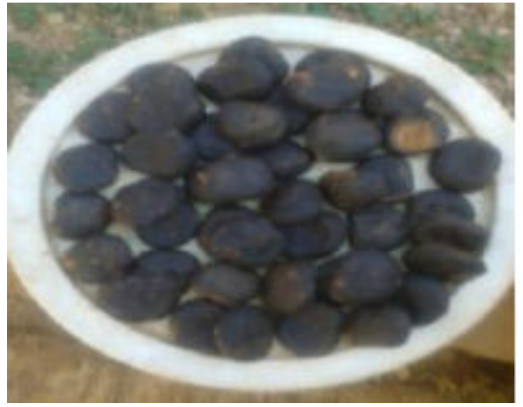

Figure 3: Seeds after drying

Determination of Mechanical Properties of Ugu Seeds

The mechanical properties were determined with the aid of a Universal Testing Machine (Testometric M500$100 \mathrm{AT}, 100 \mathrm{kN}$ ) at the laboratory of the National Centre for Agricultural Mechanization (NCAM), Ilorin-Lokoja Expressway Kwara State, Nigeria. All the mechanical properties were determined on the principal diameters (i.e. minor, intermediate and major) for each of the seed variety. 50 seeds were used under each variety on the principal diameter.

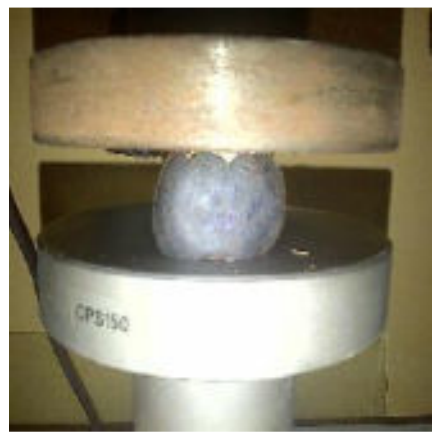

Figure 4: Major diameter

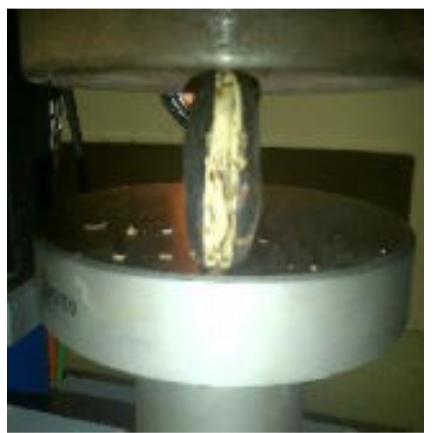

Figure 5: Minor diameter

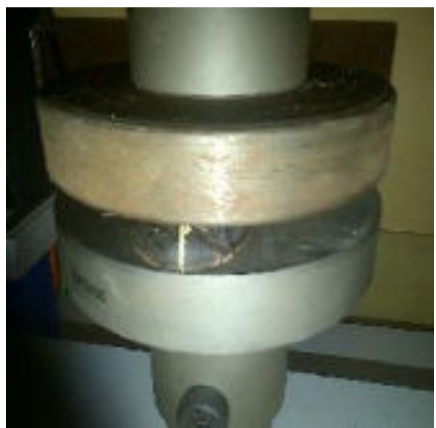

Figure 6: Intermediate diameter 
Michael Mayokun Odewole et al.,

\section{RESULTS}

Summary of results on major, intermediate and minor diameters for three varieties used are presented in Tables 1,2 and 3 respectively. Comparison of results between the three varieties(NHTo-1, NHTo-2 and NHTo-3) and on the diameters for energy at break, force at break, strain at break and stress at break are presented in Figures 7, 8, 9 and 10 respectively. From the tables and figures, there
Sci. Technol. Arts Res. J., July-Sep 2015, 4(3): 187-191

were variations in the values of mechanical properties of emphasis i.e energy at break, force at break, strain at break and stress at break. These variations could basically be due to the influence of seed varieties in the sense that, the three varieties may not have the same characteristics even though they are from the same crop family.

Table 1: Summary of determined mechanical properties on major diameter

\begin{tabular}{lccc}
\hline \multicolumn{1}{c}{ Properties } & NHTo-1 & NHTo-2 & NHTo-3 \\
\hline Force at Peak $(\mathrm{N})$ & $76.545 \pm 0.841$ & $163.143 \pm 59.575$ & $240.000 \pm 123.160$ \\
Force at Yield $(\mathrm{N})$ & $51.455 \pm 23.054$ & $136.571 \pm 49.030$ & $99.286 \pm 56.588$ \\
Force at Break $(\mathrm{N})$ & $28.400 \pm 14.064$ & $120.857 \pm 77.823$ & $224.857 \pm 129.892$ \\
Deformation at Peak $(\mathrm{mm})$ & $1.604 \pm 0.561$ & $1.276 \pm 0.658$ & $3.461 \pm 2.323$ \\
Deformation at Yield $(\mathrm{mm})$ & $0.786 \pm 0.227$ & $0.875 \pm 0.412$ & $1.140 \pm 0.852$ \\
Deformation at Break $(\mathrm{mm})$ & $2.209 \pm 0.841$ & $1.574 \pm 0.633$ & $3.656 \pm 2.202$ \\
Strain at Peak $(\%)$ & $1.604 \pm 0.561$ & $4.252 \pm 2.194$ & $10.489 \pm 7.040$ \\
Strain at Yield $(\%)$ & $0.786 \pm 0.227$ & $2.916 \pm 1.374$ & $3.455 \pm 2.582$ \\
Strain at Break $(\%)$ & $2.209 \pm 0.841$ & $5.247 \pm 2.108$ & $11.079 \pm 6.672$ \\
Stress at Yield $\left(\mathrm{N} / \mathrm{mm}^{2}\right)$ & $0.236 \pm 0.104$ & $0.719 \pm 0.231$ & $0.678 \pm 0.349$ \\
Stress at Break $\left(\mathrm{N} / \mathrm{mm}^{2}\right)$ & $0.133 \pm 0.069$ & $0.634 \pm 0.404$ & $1.557 \pm 0.837$ \\
Stress at Peak $\left(\mathrm{N} / \mathrm{mm}^{2}\right)$ & $0.350 \pm 0.072$ & $0.859 \pm 0.292$ & $1.666 \pm 0.801$ \\
Young's Modulus $\left(\mathrm{N} / \mathrm{mm}^{2}\right)$ & $34.441 \pm 10.164$ & $29.850 \pm 10.450$ & $22.026 \pm 11.271$ \\
Energy to Break $(\mathrm{Nm})$ & $0.097 \pm 0.044$ & $0.17 \pm 0.1093$ & $0.526 \pm 0.481$ \\
Energy to Peak $(\mathrm{Nm})$ & $0.073 \pm 0.028$ & $0.141 \pm 0.097$ & $0.497 \pm 0.497$ \\
Energy to Yield $(\mathrm{Nm})$ & $0.024 \pm 0.019$ & $0.074 \pm 0.064$ & $0.087 \pm 0.116$ \\
\hline
\end{tabular}

Table 2: Summary of determined mechanical properties on intermediate diameter

\begin{tabular}{lccc}
\hline \multicolumn{1}{c}{ Properties } & NHTo-1 & NHTo-2 & NHTo-3 \\
\hline Force at Peak $(\mathrm{N})$ & $304.000 \pm 103.116$ & $1978.286 \pm 881.598$ & $2069.143 \pm 1027.751$ \\
Force at Yield $(\mathrm{N})$ & $157.000 \pm 155.251$ & $1509.714 \pm 1130.125$ & $1719.571 \pm 1204.114$ \\
Force at Break $(\mathrm{N})$ & $233.667 \pm 134.616$ & $1887.286 \pm 831.053$ & $2043.857 \pm 1050.785$ \\
Deformation at Peak $(\mathrm{mm})$ & $3.680 \pm 1.303$ & $3.499 \pm 1.021$ & $4.060 \pm 1.092$ \\
Deformation at Yield $(\mathrm{mm})$ & $1.350 \pm 0.364$ & $2.709 \pm 1.360$ & $2.942 \pm 1.061$ \\
Deformation at Break $(\mathrm{mm})$ & $3.739 \pm 1.345$ & $3.565 \pm 0.967$ & $4.208 \pm 1.275$ \\
Strain at Peak $(\%)$ & $3.680 \pm 1.303$ & $26.914 \pm 7.856$ & $33.830 \pm 9.101$ \\
Strain at Yield $(\%)$ & $1.350 \pm 0.364$ & $20.842 \pm 10.461$ & $24.517 \pm 8.840$ \\
Strain at Break $(\%)$ & $3.739 \pm 1.345$ & $27.422 \pm 7.439$ & $35.069 \pm 10.629$ \\
Stress at Yield $\left(\mathrm{N} / \mathrm{mm}^{2}\right)$ & $0.148 \pm 0.136$ & $1.623 \pm 1.250$ & $1.679 \pm 1.072$ \\
Stress at Break $\left(\mathrm{N} / \mathrm{mm}^{2}\right)$ & $0.225 \pm 0.111$ & $2.003 \pm 0.918$ & $2.040 \pm 0.964$ \\
Stress at Peak $\left(\mathrm{N} / \mathrm{mm}^{2}\right)$ & $0.297 \pm 0.076$ & $2.101 \pm 0.976$ & $2.066 \pm 0.941$ \\
Young's Modulus $\left(\mathrm{N} / \mathrm{mm}^{2}\right)$ & $10.249 \pm 7.419$ & $9.034 \pm 4.379$ & $6.866 \pm 3.302$ \\
Energy to Break $(\mathrm{Nm})$ & $0.520 \pm 0.056$ & $2.551 \pm 1.160$ & $2.604 \pm 0.910$ \\
Energy to Peak $(\mathrm{Nm})$ & $0.506 \pm 0.054$ & $2.468 \pm 1.102$ & $2.517 \pm 1.033$ \\
Energy to Yield $(\mathrm{Nm})$ & $0.127 \pm 0.152$ & $1.640 \pm 1.422$ & $1.781 \pm 1.289$ \\
\hline
\end{tabular}

Table 3: Summary of determined mechanical properties on minor diameter

\begin{tabular}{lccc}
\hline Properties & NHTo-1 & NHTo-2 & NHTo-3 \\
\hline Force at Peak $(\mathrm{N})$ & $89.100 \pm 30.079$ & $309.000 \pm 182.339$ & $395.714 \pm 98.573$ \\
Force at Yield $(\mathrm{N})$ & $43.700 \pm 20.210$ & $181.429 \pm 171.908$ & $193.143 \pm 85.300$ \\
Force at Break $(\mathrm{N})$ & $53.500 \pm 47.964$ & $233.571 \pm 171.267$ & $363.857 \pm 107.606$ \\
Deformation at Peak $(\mathrm{mm})$ & $1.724 \pm 0.591$ & $3.447 \pm 1.596$ & $4.200 \pm 1.324$ \\
Deformation at Yield $(\mathrm{mm})$ & $0.621 \pm 0.276$ & $1.821 \pm 1.666$ & $1.513 \pm 0.822$ \\
Deformation at Break $(\mathrm{mm})$ & $1.909 \pm 0.586$ & $3.729 \pm 1.699$ & $4.356 \pm 1.358$ \\
Strain at Peak $(\%)$ & $1.724 \pm 0.591$ & $9.071 \pm 4.201$ & $12.354 \pm 3.894$ \\
Strain at Yield $(\%)$ & $0.621 \pm 0.276$ & $4.792 \pm 4.385$ & $4.450 \pm 2.416$ \\
Strain at Break $(\%)$ & $1.909 \pm 0.586$ & $9.813 \pm 4.472$ & $12.813 \pm 3.995$ \\
Stress at Yield $\left(\mathrm{N} / \mathrm{mm}^{2}\right)$ & $0.345 \pm 0.187$ & $1.573 \pm 1.533$ & $1.401 \pm 0.581$ \\
Stress at Break $\left(\mathrm{N} / \mathrm{mm}^{2}\right)$ & $0.412 \pm 0.421$ & $2.016 \pm 1.522$ & $2.672 \pm 0.838$ \\
Stress at Peak $\left(\mathrm{N} / \mathrm{mm}^{2}\right)$ & $0.695 \pm 0.276$ & $2.653 \pm 1.580$ & $2.911 \pm 0.797$ \\
Young's Modulus $\left(\mathrm{N} / \mathrm{mm}^{2}\right)$ & $42.640 \pm 20.721$ & $26.721 \pm 4.391$ & $29.536 \pm 10.877$ \\
Energy to Break $(\mathrm{Nm})$ & $0.095 \pm 0.044$ & $0.765 \pm 3.409$ & $1.040 \pm 0.548$ \\
Energy to Peak $(\mathrm{Nm})$ & $0.089 \pm 0.043$ & $0.694 \pm 0.606$ & $0.985 \pm 0.520$ \\
Energy to Yield $(\mathrm{Nm})$ & $0.016 \pm 0.012$ & $0.302 \pm 0.508$ & $0.195 \pm 0.181$ \\
\hline
\end{tabular}


Michael Mayokun Odewole et al.,

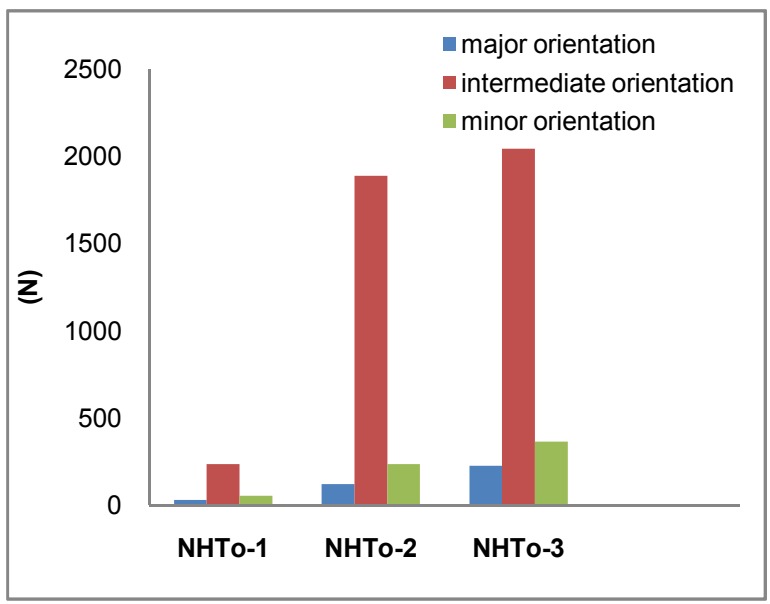

Figure 7: Force at Break Comparison

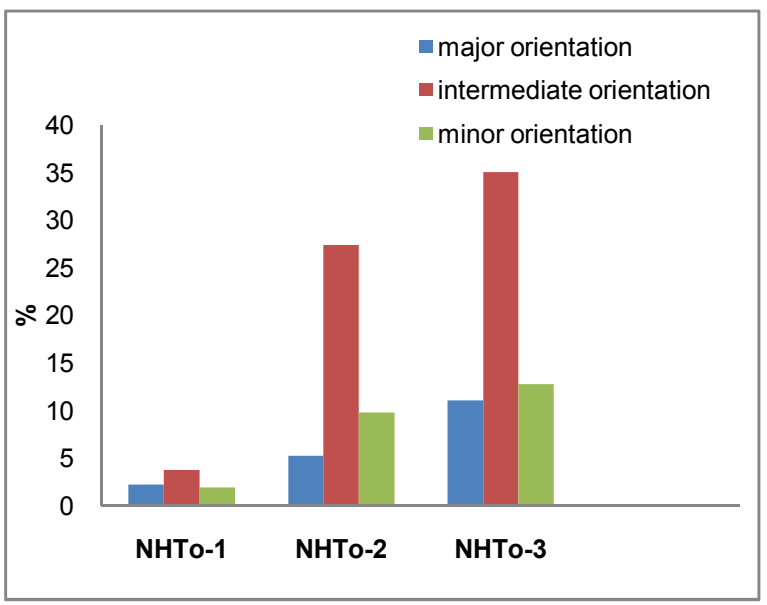

Figure 9: Comparison of strain at break

\section{DISCUSSION}

\section{Force at Break}

The comparison of the force at break is presented in Figure 7. From the figure, it is clearly seen that the highest values of force at break is noticed at the intermediate diameter for all the three varieties of seed. Although, NHTo-3 variety, required the highest force at break compared to other two varieties (NHTo-1 and NHTo-2). From Tables 1, 2 and 3, NHTo-1 had the lowest force at break on major diameter with mean value of $28.400 \pm$ $14.064(\mathrm{~N})$ and highest force on the intermediate diameter with a value of $233.667 \pm 134.616(\mathrm{~N})$. This pattern was also noticed for other two varieties with the following mean values (lowest and highest) on major and intermediate diameters respectively: NHTo-2 (120.857士 $77.823(\mathrm{~N})$ and 1887.286 $\pm 831.053(\mathrm{~N}))$ and NHTo$3(224.857 \pm 129.892(\mathrm{~N})$ and $2043.857 \pm 1050.785(\mathrm{~N}))$. All the values of force obtained were lower than what Dagwa and Ibhadode (2008) got in the determination of mean rupture force $(3174.52 \pm 270.70-3884.61 \pm 878.16 \mathrm{~N})$ for palm kernel shell. The mean fracture force required for breaking palm fruit, kernel and nut were reported to be $0.39 \mathrm{~N}, 11 \mathrm{~N}$ and $0.92 \mathrm{~N}$ respectively by Davies (2012); while Owolarafe et al. (2007) reported values of $2301 \mathrm{~N}$ and $1149 \mathrm{~N}$ for breaking dura and tenera palm kernel varieties. For almond seed, Aktas et al. (2007) said the
Sci. Technol. Arts Res. J., July-Sep 2015, 4(3): 187-191

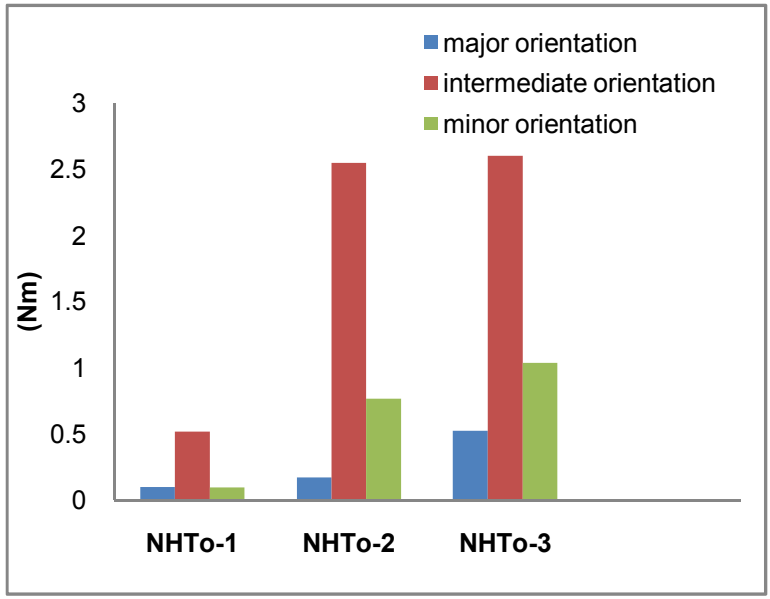

Figure 8: Energy to Break Comparison

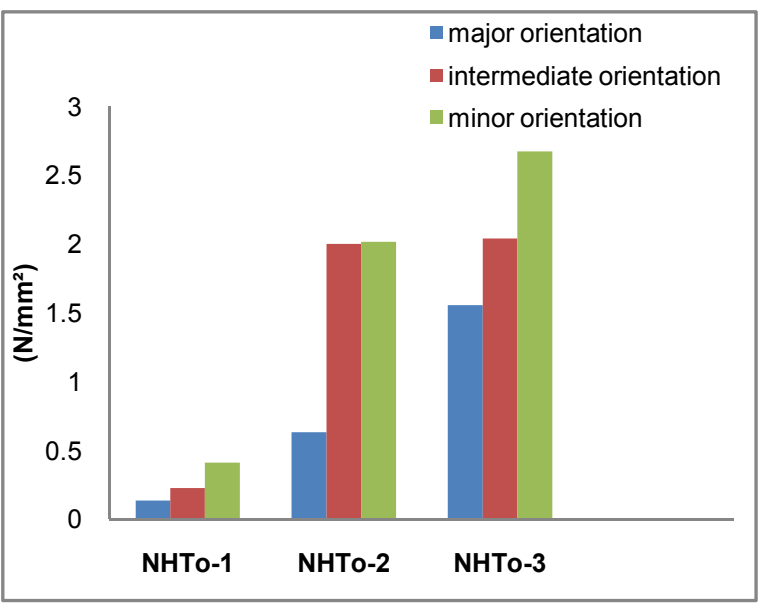

Figure 10: Comparison of stress at break

force needed to rupture the seed was between $533.4 \mathrm{~N}$ and $126.9 \mathrm{~N}$.

\section{Energy at Break}

Figure 8 shows the comparison of energy to break the seed. From the figure, the highest energy to break was obtained on the intermediate diameter for the three seed varieties with major diameter having the lowest. From Tables 1, 2 and 3, NHTo-1, NHTo-2 and NHTo-3 have the following determined values of energy at break on their diameters respectively: major diameter $(0.097 \pm 0.044 \mathrm{Nm}$, $0.170 \pm 1.093 \mathrm{Nm}$ and $0.526 \pm 0.481 \mathrm{Nm})$; intermediate diameter $(0.520 \pm 0.056,2.551 \pm 1.160$ and $2.604 \pm 0.910$ $\mathrm{Nm})$; minor diameter $(0.095 \pm 0.044 \mathrm{Nm}, 0.765 \pm 3.409 \mathrm{Nm}$ and $1.040 \pm 0.548 \mathrm{Nm}$ ). Khazaei (2008) reported that the energy required to break almond was $443 \mathrm{MJ}$.

\section{Strain at Break}

The comparison for strain at break of the seed is shown Figure 9. From the figure, the intermediate orientation of the diameter gave highest values of strain at break for all the three varieties of seed. From Tables 1, 2 and 3, NHTo-1, NHTo-2 and NHTo-3 have the following determined values of strain at break on the orientation of their diameters respectively: major $(2.209 \pm 0.841,5.247 \pm$ 2.108 and $11.079 \pm 6.672 \%)$, intermediate $(3.739 \pm 1.345$, $27.422 \pm 7.439$ and $35.069 \pm 10.629 \%)$ and minor (1.909 \pm 
Michael Mayokun Odewole et al.,

$0.586,9.813 \pm 4.4721$ and $12.813 \pm 3.995 \%$ ). Mayor et al., (2007) reported that the range of failure strain of fresh pumpkin was 0.42-0.71. Also, Sunmonu et al., (2015) reported a range of $19.74-38.58$ for white and red almond seed.

\section{Stress at Break}

From Figure 10, NHTo-1 has the lowest stress at break among the three varieties at all the three orientations of seed diameter. Also, NHTo-3 gave the highest stress at break on the minor orientation of the diameter. From Tables 1, 2 and 3, NHTo-1, NHTo-2 and NHTo-3 have the following determined values of stress at break on the orientation of their diameters respectively: major $\quad(0.133 \pm 0.069, \quad 0.634 \pm 0.404$ and $1.557 \pm 0.837$ $\left.\mathrm{N} / \mathrm{mm}^{2}\right)$; intermediate $(0.225 \pm 0.111,2.003 \pm 0.918$ and $\left.2.040 \pm 0.964 \mathrm{~N} / \mathrm{mm}^{2}\right)$ and minor $(0.412 \pm 0.421,2.016 \pm$ 1.522 and $2.672 \pm 0.838 \mathrm{~N} / \mathrm{mm}^{2}$ ).

\section{CONCLUSIONS}

The following conclusions were deduced from the determination of the mechanical properties of Ugu Seed; the mean values of mechanical properties (force, energy, strain and stress at break) on the major, intermediate and minor diameters increased from NHTo-1 to NHTo-3.

The ranges of mean values at different orientations of diameters were as stated in the brackets: on the major diameter, the force at break was $(28.400 \pm 14.064$ to $224.857 \pm 129.892 \mathrm{~N})$, the energy at break was $(0.097 \pm$ $0.044 \mathrm{Nm}$ to $0.526 \pm 0.481 \mathrm{Nm}$ ), the strain at break was $(2.209 \pm 0.841$ to $11.079 \pm 6.672 \%)$ and the stress at break was $\left(0.133 \pm 0.069\right.$ to $\left.1.577 \pm 0.837 \mathrm{~N} / \mathrm{mm}^{2}\right)$. On the intermediate diameter, the force at break was (233.667 \pm 134.616 to $2043.857 \pm 1050,785 \mathrm{~N}$ ), the energy at break was $(0.520 \pm 0.054$ to $2.604 \pm 0.910 \mathrm{Nm})$, the strain at break was (3.739 \pm 1.345 to $35.069 \pm 10.629 \%)$, and the stress at break was $\left(0.225 \pm 0.111\right.$ to $\left.2.040 \pm 0.964 \mathrm{~N} / \mathrm{mm}^{2}\right)$. On the minor diameter, the force at break was $(53.500 \pm 47.964$ to $363.857 \pm 107.606 \mathrm{~N})$, the energy at break was $(0.095 \pm$ 0.044 to $1.040 \pm 0.548 \mathrm{Nm}$ ), the strain at break was $(1.909 \pm 0.586$ to $12.813 \pm 3.995 \%)$, and the stress at break was $\left(0.412 \pm 0.421\right.$ to $\left.2.672 \pm 0.838 \mathrm{~N} / \mathrm{mm}^{2}\right)$.

NHTo-1 seed variety gave the best crack and did least damage to the kernel on the minor diameter with the mean values of force at break of $53.500 \pm 47.964 \mathrm{~N}$. The implication of this is that when a machine for cracking is to be designed and constructed, ugu seeds should be fed into the cracking medium in such a way that would make them to receive the cracking force of $53.500 \pm 47.964 \mathrm{~N}$ on their minor diameter orientation.

\section{Conflict of Interest}

Authors declared no conflict of interest

\section{Acknowledgements}

Authors wish to strongly acknowledge the National Horticultural Research (NIHORT) Institute Ibadan, Nigeria for the classification of seed varieties used and the National Centre for Agricultural Mechanization, IlorinLokoja, Express Way, Kwara State, Nigeria for providing a highly conducive environment for the experiment.
Sci. Technol. Arts Res. J., July-Sep 2015, 4(3): 187-191

\section{REFERENCES}

Aktas, T., Pola, R and Atay, V. (2007). Comparison of Mechanical Properties of some Selected Almond Cultivars with Hard and Soft Shells under Compression Loading. Journal of Food Engineering. 30(6): 773-789.

Alegbejo, J.O .(2012). Production, Marketing, Nutritional Value and Uses of Fluted Pumpkin(Telfairia Occidentalis Hook. F). Journal of Biological Science and Bioconsevation 4: 20-24.

Christian, A. (2006). Studies of Selected Physicochemical Properties of Fluted Pumpkin (Telfaria Occidentalis Hook F.) Seed Oil and Tropical Almond (Terminalia Catappia, L.) Seed Oil. Pakistan Journal of Nutrition 5(4): 306-307.

Dagwa, I.M., and Ibhadode, A.O. (2008). Some Physical and Mechanical Properties of Palm Kernel Shell (PKS). Botswana Journal of Technology 17(2): 1019-1593.

Davies, R.M. (2012). Physical and Mechanical Properties of Palm Fruit, Kernel and Nut. Journal of Agricultural Technology 8(7): 2147-2156.

Grubben, G.J.H., and Denton, O.A. (2004). Plant Resources of Tropical Africa 2 vegetables, PROTA Foundation, Wageningen, Netherlands Backhuys Publishers, Leiden, Netherlands CTA, Wageningen Netherlands. Pp 668.

Horsfall, M.J. and Spiff, I.A. (2005). Equilibrium Sorption Study of $\mathrm{A} 13+, \mathrm{CO} 2+$ and $\mathrm{Ag}+$ in Aqueous Solution by Fluted Pumpkin (Telfaria Occidentalis Hook F) Waste Biomass. Acta Chemistry of Slovia 52: 174-181.

Khazaei, J. (2008). Characteristics of Mechanical Strength and Water Absorption in Almond and its Kernel. Cerciteria Agronimice in Moldova 41(1): 37-51.

Mayor, L., Cunha, R.L. and Sereno, A.M. (2007). Relation between Mechanical Properties and Structural Change during Osmotic Dehydration of Pumpkin. Food Research International 40: 448-460.

Mohsenin, N.N. (1970). Physical Properties of Plant and Animal Materials. Gordon and Breach. Science Publisher New York. Vol. 1:1-742.

Nkang. A., Omokaro. D., Egbe, A. and Amanke, G. (2003) Variations in Fatty Acid Proportion During Desiccation of Telfairia Occidentalis Seeds Harvested at Physiological and Agronomic Maturity. African Journal of Biotechnology 2(2): 33-39.

Ojiako, O.A. and Igwe, C.U. (2008). The Nutritive, AntiNutritive and Hepatotoxic Properties of Trichosanthes Anguina (Snake Tomato) Fruits from Nigeria. Pakistan Journal of Nutrition 7(1): 85-89.

Owolarafe, O.K., Olabiye, M.T., and Faborode, M.O. (2007). Physical and Mechanical Properties of Two Varieties of Fresh Oil Palm Fruit. Journal of Food Engineering 78: 1228-1232.

Schippers, R.R. (2002). African Indigenous Vegetables, an Overview of the Cultivated Species 2002. Revised edition on CD-ROM. National Resources International Limited Aylesford, United Kingdom.

Sunmonu, M.O., lyanda, M.O., Odewole, M.M and Moshood A.N (2015). Determination of Some Mechanical Properties of Almond Seeds Related to Design of Food Processing Machine. Nigerian Journal of Technological Development 12(1): 22-26. 